\title{
CONTRASTING PATTERNS OF QUANTITATIVE AND NEUTRAL GENETIC VARIATION IN LOCALLY ADAPTED POPULATIONS OF THE NATTERJACK TOAD, BUFO CALAMITA
}

\author{
Ivan Gomez-Mestre ${ }^{1,2}$ and Miguel Tejedo ${ }^{1}$ \\ ${ }^{1}$ Departamento de Biología Evolutiva, Estación Biológica de Doñana, Consejo Superior de Investigaciones Cientificas, \\ Avenida Maria Luisa s/n, Pabellon del Perú, 41013-Sevilla, Spain
}

\begin{abstract}
The relative importance of natural selection and genetic drift in determining patterns of phenotypic diversity observed in nature is still unclear. The natterjack toad (Bufo calamita) is one of a few amphibian species capable of breeding in saline ponds, even though water salinity represents a considerable stress for them. Results from two common-garden experiments showed a pattern of geographic variation in embryonic salinity tolerance among populations from either fresh or brackish environments, consistent with the hypothesis of local adaptation. Full-sib analysis showed increased variation in survival among sibships within population for all populations as osmotic stress was increased (broad-sense heritability increased as salinity raised). Nevertheless, toads native to the brackish water environment had the highest overall survival under brackish conditions. Levels of population genetic differentiation for salinity tolerance were higher than those of neutral genetic differentiation, the latter obtained through the analysis of eight microsatellite loci. Microsatellite markers also revealed little population differentiation, lack of an isolationby-distance pattern, and moderate gene flow connecting the populations. Therefore, environmental stress tolerance appears to have evolved in absence of geographic isolation, and consequently we reject the null hypothesis of neutral differentiation.
\end{abstract}

Key words. _ Bufo, $\mathrm{F}_{\mathrm{ST}}$, local adaptation, microsatellite loci, population differentiation, $\mathrm{Q}_{\mathrm{ST}}$, salinity tolerance.

Natural selection is a very powerful and widespread factor driving microevolutionary change (Endler 1986; Kingsolver et al. 2001). However, the extent to which natural selection and the adaptive responses of organisms should be held responsible for the patterns of biological diversity is far from settled. Because the molecular characterisation of genetic variation became technically feasible, a growing body of literature has been produced comparing this sort of genetic variation with estimates of quantitative genetic variation in morphological, behavioral, and life-history traits (for reviews, see Merilä and Crnokrak 2001; McKay and Latta 2002). Comparing patterns of population genetic differentiation in neutral marker loci with those of quantitative traits permits inferences about the relative role of selection in population divergence, by contrasting the degree of adaptive change with that of differentiation due solely to drift (Lande 1992; Lynch 1996; Merilä and Crnokrak 2001; Reed and Frankham 2001; McKay and Latta 2002). Thus, estimates of neutral genetic divergence provide a null hypothesis to the alternative hypothesis of adaptive divergence (Lynch 1990; Spitze 1993; Podolsky and Holtsford 1995; Schluter 2000). Comparisons of the degree of genetic population subdivision for quantitative traits $\left(Q_{\mathrm{ST}}\right)$ and neutral allelic divergence found between populations $\left(F_{\mathrm{ST}}\right)$ have showed that generally $Q_{\mathrm{ST}}$ is on average greater than $F_{\mathrm{ST}}$ (Merilä and Crnokrak 2001; McKay and Latta 2002). When population differentiation in neutral genetic markers equals that exhibited by quantitative traits $\left(Q_{\mathrm{ST}}=F_{\mathrm{ST}}\right)$, the null hypothesis cannot be rejected and drift cannot be ruled out as the main causes of population divergence (Kuittinen et al. 1997; Waldmann and Andersson 1998; Lynch et al. 1999; Widén et al. 2002).

\footnotetext{
2 Present address: Department of Biology, Boston University, 5 Cummington Street, Boston, Massachusetts 02215; E-mail: igmestre@bu.edu.
}

When $Q_{\mathrm{ST}}$ and $F_{\mathrm{ST}}$ differ significantly, selection is plausibly responsible for the pattern. Directional or disruptive selection would have promoted population divergence when $Q_{\mathrm{ST}}>$ $F_{\mathrm{ST}}$, while stabilizing selection would have opposed divergence in quantitative traits despite drift if $Q_{\mathrm{ST}}<F_{\mathrm{ST}}$ (Prout and Barker 1993; Spitze 1993; Long and Singh 1995; Morgan et al. 2001; Petit et al. 2001; Steinger et al. 2002; Storz 2002).

It has been noted that quantitative trait variation would be a better indicator of the evolutionary potential of populations than neutral genetic variation and that conservation studies would benefit from incorporating this type of information (Lynch 1996; Storfer 1996; Knapp and Rice 1998; Podolsky 2001). But the converse is also true. The joint analysis of quantitative traits and neutral marker loci in evolutionary biology not only provides a null expectation, but it also provides a quantitative description of the population structure in which population differentiation has taken place and the amount of gene flow that selection has opposed (if at all).

We compare the pattern of genetic variation at both microsatellite loci and osmotic stress tolerance in five populations of the natterjack toad (Bufo calamita) that inhabit either freshwater or brackish water ponds in southern Spain. Water salinity constitutes an environmental stress for amphibians due to their poor osmoregulatory capability (Balinsky 1981; Boutilier et al. 1992). Nevertheless, B. calamita is a moderate eurihaline toad, for it is associated with ponds and lakes that range from freshwater to brackish water (Balinsky 1981; Beebee 1985; Sinsch et al. 1992; Gomez-Mestre and Tejedo 2002, 2003) and occupies several inland brackish ponds in Spain. Evidence from field transplants and commongarden experiments aimed at comparing the osmotic tolerance of freshwater populations and that of brackish water ones, suggests that populations have diverged in osmotic tolerance (Gomez-Mestre and Tejedo 2003). 
Estimates of population differentiation in quantitative traits obtained from wild-caught animals can be inflated by environmental effects (Lee and Frost 2002; Palo et al. 2003). To avoid this effect, measurements of quantitative genetic variation were based on common-garden experiments involving animals in the embryonic stage (Gomez-Mestre and Tejedo 2003; M. Tejedo, I. Gomez-Mestre, and R. Reques, unpubl. data). Genetic variability in quantitative traits is known to vary depending on environmental conditions (Mitchell-Olds and Rutledge 1986; Jenkins et al. 1997; Hoffmann and Merilä 1999), although no universal pattern of increased or decreased genetic variance with increased environmental stress has been observed (Hoffmann and Parsons 1991; Bennington and McGraw 1996; Hoffmann and Merilä 1999). Consequently, estimates of population differentiation are likely to be affected by the environmental conditions under which they are being measured (Merilä and Crnokrak 2001), although this phenomenon has been addressed seldomly (but see Palo et al. 2003). In the common-garden experiments that we conducted, we reared either full-sibs or half-sibs from five populations (two populations from brackish ponds and three from freshwater ponds) under different water salinity concentrations. Thus, it was possible to study quantitative genetic variation within and among populations under different levels of water salinity.

We present an analysis of population differentiation in quantitative traits (as measured by $Q_{\mathrm{ST}}$ ) under experimentally controlled varying environmental conditions. Furthermore, we tested whether local adaptation in this system has evolved in isolation or in spite of gene flow from nonadapted populations. We address the following questions: (1) Is population differentiation in salinity tolerance greater than expected solely as a result of isolation and drift (neutral evolution)? (2) Has population differentiation occurred in geographic isolation? (3) Does quantitative trait variation within and among populations change under different environmental conditions?

\section{Materials And Methods}

\section{Populations}

The embryonic common-garden experiments from which the measurements of quantitative genetic variation were derived have been described in detail elsewhere and will only be described briefly here. One of the experiments included four populations (Fresh 1-3 and Saline 1) and involved comparisons among full-siblings within populations (GomezMestre and Tejedo 2003), while the other included only two populations (Fresh 2 and Saline 2), but compared half-sibling variation within populations (M. Tejedo, I. Gomez-Mestre, and R. Reques, unpubl. data). Three of the populations studied, Fresh 1, 2, and 3, breed in different kinds of freshwater environments, either in shallow ponds on granitic soil in different regions of Sierra Morena (Fresh 2 and 3) or in ephemeral ponds on sandy soil of Parque Natural de Doñana (Fresh 1). Two populations naturally breeding in brackish water (Saline 1 and 2) were sampled in Laguna del Taraje and Laguna de Jarales, two temporary lagoons on haline sedimentary basins in Córdoba province, $3 \mathrm{~km}$ apart from one another.

\section{Description of the Experiments}

In the full-sib/four-population experiments, between six and nine clutches from each population were sampled in early spring 2000. Embryos from each clutch were taken to the laboratory and strings of 20 embryos were randomly distributed into petri dishes assigned to either one of three water salinity levels (freshwater, $6 \mathrm{~g} / \mathrm{L}$, and $8 \mathrm{~g} / \mathrm{L}$ ). Brackish water was obtained from Saline 2 original pond and diluted with fresh water to the targeted concentrations. Each treatment (full-sib $X$ population $X$ salinity) was replicated six times and the replicates were randomized in spatially distributed blocks along shelves in the laboratory.

For the half-sib/two-population experiment, adult B. calamita were randomly sampled and crossed, yielding 30 halfsibships from Saline 2 and 14 half-sibships from Fresh 2 in winter 1998 (M. Tejedo, I. Gomez-Mestre, and R. Reques, unpubl. data). Batches of five eggs from each sibling were randomly assigned to $20-\mathrm{ml}$ wells on ice-cube racks, filled with either freshwater, $6 \mathrm{~g} / \mathrm{L}$, or $8 \mathrm{~g} / \mathrm{L}$. Each half-sib $X$ population $X$ salinity combination was replicated six times. In both experiments room temperature was kept roughly constant (range $=20-24^{\circ} \mathrm{C}$ ) and photoperiod followed a $12: 12$ cycle.

\section{Quantitative Variation Analysis}

The trait considered in both experiments was survival to 25 stage Gosner (Gosner 1960), when tadpoles begin free feeding. Survival in this context reflects osmotic stress tolerance and it has a direct link to fitness. In all cases, we used the proportion of surviving embryos in each dish or well as the response variable, instead of the survival of each individual embryo. Using a single observation per experimental container helped prevent both pseudoreplication and potential common-environment effects. However, each observation averaged over a group of siblings approximates the breeding value of the two parents (Simons et al. 1998; D. A Roff, pers. comm.), and therefore heritability estimates are obtained from the intraclass correlation itself in the case of fullsibs and twice (not four times) the value in the case of halfsibs.

For the full-sib experiment in 2000, we estimated broadsense heritability $\left(H^{2}\right)$ for each population and each salinity treatment. Variance components due to sibship and experimental block were estimated using restricted maximum-likelihood analysis with the MIXED procedure of SAS (SAS Institute 1999). Broad-sense heritability was calculated as $H^{2}$ $=\left(\mathrm{ci}_{\mathrm{S}}^{2}\right) /\left(\mathrm{ci}_{\mathrm{S}}^{2}+\mathrm{ci}_{\mathrm{B}}^{2}+\mathrm{ci}^{2}\right)$, where $\mathrm{ci}_{\mathrm{S}}^{2}, \mathrm{ci}_{\mathrm{B}}^{2}$, and $\mathrm{ci}^{2}$ were the variance components associated with differences among fullsibs within population, experimental block effect, and the error term, respectively (Falconer and Mackay 1996). In the half-sib experiment of 1998, the additive variance component $\left(\mathrm{ci}_{\mathrm{A}}^{2}\right.$ ) was calculated for each population at each salinity level using the software Quercus (Shaw 1987; Shaw and Shaw 1994). Both broad-sense and narrow-sense heritability estimates obtained from laboratory-reared progeny may be an imperfect reflection of heritability in nature, although estimates obtained in the laboratory are often strongly correlated with, and good indicators of, estimates obtained in the field (Roff 1997). 
The proportion of between-population genetic variance $\left(Q_{\mathrm{ST}}\right)$ in salinity tolerance was calculated under the different salinity conditions as $Q_{\mathrm{ST}}=\mathrm{ci}_{\mathrm{GB}}^{2} /\left(\mathrm{ci}_{\mathrm{GB}}^{2}+2 \mathrm{ci}_{\mathrm{GW}}^{2}\right)$, where $\mathrm{Ci}_{\mathrm{GB}}^{2}$ and $\mathrm{Ci}_{\mathrm{GW}}^{2}$ are the genetic variances between and within populations, respectively (Wright 1951; Lande 1992; Spitze 1993). The different variance components were estimated in both experiments by fitting a mixed linear model through restricted maximum likelihood for each salinity level and population pair using the MIXED procedure of SAS (SAS Institute 1999). For the 2000 full-sib experiment the model fitted was survival $=$ block + population + sibship (population) + residual. The average genetic variance within populations $\left(\mathrm{ci}_{\mathrm{GW}}^{2}\right)$ was estimated as the observational variance component for sibships within population. The average genetic variance between populations $\left(\mathrm{ci}_{\mathrm{GB}}^{2}\right)$ was estimated indirectly by equating it to the observational component for populations. This procedure could result in a $Q_{\mathrm{ST}}$ estimate biased upward if there was significant environmentally induced phenotypic variation among populations. In this case, we assumed that the standardized conditions of the commongarden experiments rendered environmentally induced variation negligible. In the 1998 half-sib experiment, the model fitted for each salinity level was survival $=$ population + sire (population) + dam (population) + sire $X$ dam (population) + block + residual. The average variance between populations $\left(\mathrm{ci}_{\mathrm{GB}}^{2}\right)$ was equated to the observational component for populations, while the variance within population $\left(\mathrm{ci}_{\mathrm{GW}}^{2}\right)$ was equated to twice the sire nested within population component. In both experiments, standard errors of the genetic parameter estimates were obtained using the delta method (Podolsky and Holtsford 1995; Lynch and Walsh 1998).

\section{Molecular Genetic Analysis}

Eight microsatellite loci were analyzed in the five populations. The markers used were Bcal 1, Bcal 2, Bcal 3, Bcal 4, Bcal 5, Bcal 7 (Rowe et al. 1997), Bcal 10, and Bcal 11 (Rowe et al. 2000). Tissue samples were obtained by toeclipping of adults during the breeding season at four of the five populations, randomly sampling 23-25 individuals per population. This procedure does not compromise the survival of adult toads (as revealed by subsequent recaptures of marked individuals; I. Gomez-Mestre and M. Tejedo, pers. obs.), and it is preferred over using tadpole tail tissue because the latter increases the probability of sampling siblings, and therefore inflating the inbreeding estimates (Hansen et al. 1997). However, samples had to be derived from tadpoles in Saline 2, so we sampled from disparate parts of the lagoon to maximize the chances of sampling unrelated animals.

DNA was obtained following a phenol-chloroform extraction protocol and was stocked in concentrations of $60-100$ ng/jil. The 5' to 3'-primers were labeled with a color fluorophore, either HEX, TET, or FAM. Amplification of the loci was conducted by polymerase chain reactions (PCRs) of 15 jil total volume with 5 jil of DNA. The PCR amplifications followed a $66-50^{\circ} \mathrm{C}$ touchdown procedure. PCR products of each of the eight loci for each individual sampled were aliquoted and mixed according to their abundance. An aliquot of $1.5 \mathrm{jil}$ of the resulting mix was added to $13 \mathrm{jil}$ of formamide plus 0.3 jil of Tamra 500 (Applied Biosystems, Foster City, 
TABLE 2. Pairwise estimates of population quantitative genetic differentiation $\left(Q_{\mathrm{ST}}\right)$ among the four populations considered in the fullsib experiment (A) and half-sib experiment (B). The estimates were obtained for three different water salinity levels. Mantel tests used to test for correlation between $Q_{\mathrm{ST}}$ estimates for each environment and $F_{\mathrm{ST}}$ estimates are also given.

\begin{tabular}{|c|c|c|c|c|c|c|}
\hline A & $\begin{array}{l}\text { Saline } 1 \text { vs. } \\
\text { Fresh } 1\end{array}$ & $\begin{array}{l}\text { Saline } 1 \text { vs. } \\
\text { Fresh } 2\end{array}$ & $\begin{array}{l}\text { Saline } 1 \text { vs. } \\
\text { Fresh } 3\end{array}$ & $\begin{array}{l}\text { Fresh } 1 \text { vs. } \\
\text { Fresh } 2\end{array}$ & $\begin{array}{l}\text { Fresh } 1 \text { vs. } \\
\text { Fresh } 3\end{array}$ & $\begin{array}{c}\text { Fresh } 2 \text { vs. } \\
\text { Fresh } 3\end{array}$ \\
\hline \multicolumn{7}{|l|}{ Fresh water } \\
\hline Рор & 0.005 & 0.002 & 0.004 & 0.001 & $<0.001$ & $<0.001$ \\
\hline$Q_{\mathrm{ST}}$ & 0.391 & 0.165 & 0.319 & 0.154 & $<0.001$ & 0.065 \\
\hline 2 SD CI & $0.389-0.393$ & $0.164-0.167$ & $0.318-0.320$ & $0.141-0.167$ & & $0.056-0.074$ \\
\hline Mantel & $Q_{\mathrm{ST}}$ vs. $F_{s t}$ & \multicolumn{5}{|c|}{$Z=0.051, P=0.584, r=-0.30$} \\
\hline Fam (Рop) & 0.001 & 0.002 & 0.002 & $<0.001$ & 0.003 & $<0.001$ \\
\hline$Q_{\mathrm{ST}}$ & 0.315 & 0.293 & 0.349 & $<0.001$ & 0.008 & $<0.001$ \\
\hline $2 \mathrm{SD}$ CI & $0.314-0.315$ & \multirow{2}{*}{\multicolumn{5}{|c|}{$\begin{array}{c}0.340-0.349 \\
Z=0.048, P=0.413, r=-0.15\end{array}$}} \\
\hline Mantel & $Q_{\mathrm{ST}}$ vs. $F_{\text {st }}$ & & & & & \\
\hline \multicolumn{7}{|l|}{$8 \mathrm{~g} / \mathrm{l}$} \\
\hline Pop & 0.244 & 0.446 & 0.292 & 0.018 & $<0.001$ & 0.010 \\
\hline \multicolumn{7}{|c|}{ B } \\
\hline Saline 2 vs. Fresh 2 & $\mathrm{ci}_{\text {Pop }}^{2}$ & \multicolumn{2}{|r|}{ Cisire(Pop) } & $Q_{\mathrm{ST}}$ & \multicolumn{2}{|r|}{$2 \mathrm{SD}$ CI } \\
\hline Fresh & $<0.001$ & \multicolumn{2}{|r|}{0.028} & 0.014 & \multicolumn{2}{|r|}{$0.007-0.021$} \\
\hline $6 \mathrm{~g} / \mathrm{L}$ & 0.014 & \multicolumn{2}{|r|}{0.005} & 0.211 & \multicolumn{2}{|r|}{$0.188-0.233$} \\
\hline $8 \mathrm{~g} / \mathrm{L}$ & 0.071 & \multicolumn{2}{|r|}{0.020} & 0.497 & \multicolumn{2}{|r|}{$0.483-0.510$} \\
\hline
\end{tabular}

CA) standard. The samples were then vortexed, heated at $90^{\circ} \mathrm{C}$ for $5 \mathrm{~min}$, and then analyzed in a fluorescence-based automatic fragment analyzer (ABI-PRISM 310 Genetic Analyzer, Applied Biosystems). Allele sizes for each locus were resolved by comparison of the peaks obtained to those yielded by the Tamra 500 standard using the GeneScan 3.1.2 version (Applied Biosystems). Allele frequencies, mean number of alleles per locus, and observed and expected heterozygosities were analyzed using Microsatellite Analyzer (MSA; Dieringer and Schlotterer 2003) and Arlequin (Schneider et al.

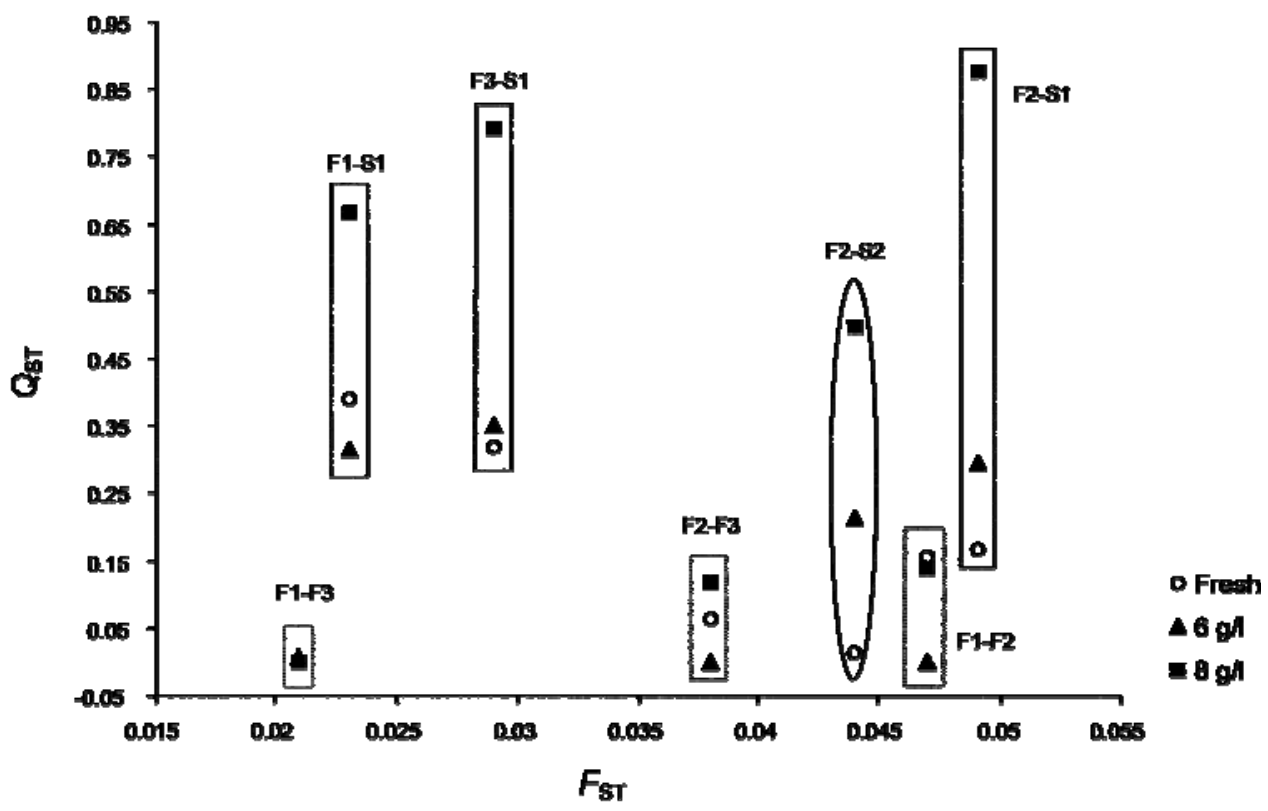

FIG. 1. $Q_{\mathrm{ST}}$ versus $F_{\mathrm{ST}}$ scatterplot. Each pairwise population comparison is associated with one $F_{\mathrm{ST}}$-value and three $Q_{\mathrm{ST}}$-values, one per experimental salinity level applied to the embryos. Ranges of $Q_{\mathrm{ST}}$-values between any two freshwater populations $\left(\mathrm{F}_{x}-\mathrm{F}_{y}\right)$ are framed with dashed rectangles, while solid line rectangles frame fresh-brackish population pairs $\left(\mathrm{F}_{x}-\mathrm{S}_{y}\right)$. The oval encircles the distances estimated from the half-sib experiment. 


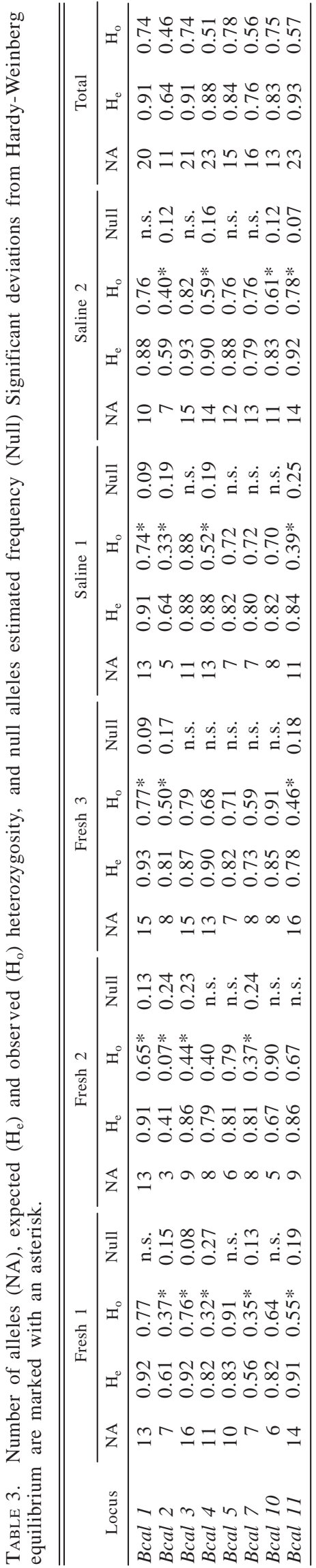

2000) software packages. Tests for linkage disequilibrium and departures from Hardy-Weinberg expectations were performed using the Markov chain method, with 10,000 permutations. Population differentiation was analyzed computing $F_{\mathrm{ST}}$ estimators (Weir and Cockerham 1984) and their confidence intervals through 10,000 parametric bootstrapping with both MSA and Arlequin software packages. When multiple comparisons were made, a sequential Bonferroni correction of the significance level was applied using a global significance level of 0.05 (Rice 1989). A nested molecular analysis of variance (nested AMOVA) was carried out using Arlequin to compare genetic diversity between and within populations, as well as between ecological environments (fresh and brackish), grouping populations in either freshwater or brackish water populations. The existence of a geographic pattern of molecular genetic variation was analyzed through Mantel tests carried out between matrices of logtransformed geographic distances and odds-transformed genetic distances $\left(F_{\mathrm{ST}} /\left[1-F_{\mathrm{ST}}\right]\right.$; Rousset 1997) using isolationby-distance (IBD) software (Bohonak 2002). The same software and statistical technique were also used to test for a geographic pattern of quantitative variation and correlation between molecular and quantitative distances. Odds from $Q_{\mathrm{ST}}$ estimates were used instead of the original values for these analyses.

\section{RESUlts}

\section{Quantitative Genetic Variation}

As reported elsewhere (Gomez-Mestre and Tejedo 2003; M. Tejedo, I. Gomez-Mestre, and R. Reques, unpubl. data), survival differed significantly across salinity levels in both experiments. There were significant differences in mean population survival across salinity levels: those populations native to brackish ponds experienced higher survival under brackish water conditions, resulting in significant population $X$ salinity interactions (Table 1 ). In the half-sib experiment (1998), Saline 2 seemed to have a larger additive genetic component than Fresh 2, although this may just reflect differences in our statistical power between populations (twice as many siblings analyzed in Saline 2). Although often not significantly different from zero, additive genetic variances seemed to increase with increasing osmotic stress (Table 1), while narrow-sense heritability decreased or remained zero. The full-sib experiment (2000), in which additive and nonadditive effects were undistinguishable, showed increased broad-sense heritability with increased salinity. In this case the statistical power was not greater for the brackish water population than for the freshwater ones, but differences among siblings were more pronounced in Saline 1 (Table 1).

Most estimates of quantitative genetic distances between population pairs $\left(Q_{S T}\right)$ increased as salinity increased (see Table 2), showing that differences in salinity tolerance among populations broadened with increased osmotic stress. Furthermore, $Q_{S T}$ estimates measured between any two freshwater populations were consistently smaller than freshwater versus brackish water population pairs, suggesting local adaptation of both Saline 1 and Saline 2 (Fig. 1). There is a significant positive correlation between $Q_{\mathrm{ST}}$ and heritability (including narrow- and broad-sense) estimates for the brack- 
TABLE 4. Nested molecular analysis of variance, where df stands for degrees of freedom, SS for sum of squares, Varcomp for variance components, and \%Var for proportion of total variance accounted for by each source.

\begin{tabular}{lrrrr}
\hline \multicolumn{1}{c}{ Source } & \multicolumn{1}{c}{ df } & \multicolumn{1}{c}{ SS } & Varcomp & \% Var \\
\hline Fresh vs. brackish & 1 & 7.78 & 0.018 & 0.64 \\
Among populations within pond type & 3 & 17.40 & 0.070 & 2.45 \\
Within populations & 215 & 591.31 & 2.750 & 96.91 \\
Total & 219 & 616.48 & 2.838 & 100 \\
\hline
\end{tabular}

ish-fresh pairwise population comparisons $\left(r_{\mathrm{s}}=0.599, P=\right.$ 0.039, $N=12$ ), whereas the correlation for the pairwise freshfresh population comparisons was nonsignificant $\left(r_{\mathrm{s}}=\right.$ $-0.383, P=0.308, N=9$ ). Tests for correlation between matrices of quantitative and neutral genetic distances were performed at each salinity level for the full-sib experiment using Mantel tests, and were all found to be nonsignificant (see Table 2A).

\section{Molecular Variation and Population Differentiation}

Pooled gene diversity was high, ranging between 0.64 and 0.93 among populations (Table 3 ). All loci were polymorphic, and the mean number of alleles per locus ranged between 11 and 23. Significant departures from Hardy-Weinberg expectations (considering heterozygote deficit the alternative hypothesis) were detected in different loci across all populations. Because allelic diversity was considerable and the primers used to amplify the microsatellite loci were originally designed for populations much less diverse (Beebee and Rowe 2000), nonamplifying alleles were assumed to be the cause of the heterozygote deficiencies observed. Estimated null allele frequency for each locus and population was calculated following Brookfield (1996) and is shown in Table 3. Analyses ran excluding the two loci with higher presumed incidence of null alleles (loci Bcal 2 and Bcal 11) were not qualitatively different from those ran on the entire dataset, and therefore all loci were included in the final analyses.

Results from the nested AMOVA indicated a lack of population substructuring such that $96.9 \%$ of overall variation was held within populations (Table 4). The ecological distinction between brackish and freshwater populations was not supported by the analysis of microsatellite markers, since only $0.6 \%$ of the total variance could be attributed to differences between these two groups.

Fixation indices $\left(F_{S T}\right)$ were generally low, ranging from 0.0109 to 0.0486 , and four out of 10 pairwise comparisons gave fixation indices not significantly different from zero. Fresh 1 was undifferentiated from Fresh 3 and from the two brackish populations, which in turn did not significantly dif- fer from one another (Table 5). The fixation index over all loci and all populations was low $\left(F_{S T}=0.029\right)$ but significantly different from zero. The pattern of neutral genetic distances among populations showed no correlation with that of geographical distances (Mantel test, $F_{S T} /\left[1-F_{S T}\right]$ vs. $\log$ [geographic distance]; $Z=0.624, P=0.29$ ), rejecting the hypothesis of isolation by distance. The average level of gene flow estimated in the system was $\mathrm{Nm}=4.3$.

\section{Discussion}

In agreement with previous studies (Gomez-Mestre and Tejedo 2003; M. Tejedo, I. Gomez-Mestre, and R. Reques, unpubl. data) salinity tolerance in B. calamita seemed to have a genetic basis, and significant variation within populations was found with both the full-sib and the half-sib approach. However, the analysis of variation among full-sibs confounds additive, dominance, and common environment effects (such as maternal effects) into the term "genetic variance" (Falconer and MacKay 1996). Results of this study indicated that heritability of the trait increased as the osmotic stress increased, as differences among full-sibs became accentuated (Table 1). However, the more informative analysis of halfsibs revealed that narrow-sense heritability may actually be decreasing as salinity increases. This apparent contradiction is most likely caused by the presence of nonadditive components (dominance and epistasis) and maternal effects, that may be sensitive to the level of stress (M. Tejedo, I. GomezMestre, and R. Reques, unpubl. data).

The $B$. calamita populations studied vary in their degree of salinity tolerance (Gomez-Mestre and Tejedo 2003). These differences are reflected in different population pairs showing very different ranges of $Q_{\mathrm{ST}}$-values under the different salinity conditions. However, the emergent pattern was not random, as higher $Q_{\mathrm{ST}}$-values were found for brackish-fresh population pairs than for fresh-fresh population pairs (Figs. 1, 2) indicating stronger quantitative differentiation between brackish and freshwater populations than among freshwater populations. Nevertheless, as indicated above for the case of within population variation, $Q_{\mathrm{ST}}$-values computed from fullsibs designs are likely to be biasing the estimate of population

TABle 5. Pairwise fixation indices ( $F_{\mathrm{ST}}$, lower diagonal) and geographic distances (km, upper diagonal). $F_{\mathrm{ST}}$ estimates marked with an asterisk were not significantly different from zero.

\begin{tabular}{|c|c|c|c|c|c|}
\hline & Fresh 1 & Fresh 2 & Fresh 3 & Saline 1 & Saline 2 \\
\hline Fresh 1 & - & 190 & 114 & 195 & 200 \\
\hline Fresh 2 & $0.047(0.019-0.070)$ & - & 85 & 80 & 85 \\
\hline Fresh 3 & $0.021 *(-0.003-0.055)$ & $0.038(0.016-0.055)$ & - & 130 & 135 \\
\hline Saline 2 & $0.012 *(0.002-0.020)$ & $0.044(0.19-0.070)$ & $0.024(0.001-0.056)$ & $0.011 *(0.000-0.023)$ & - \\
\hline
\end{tabular}




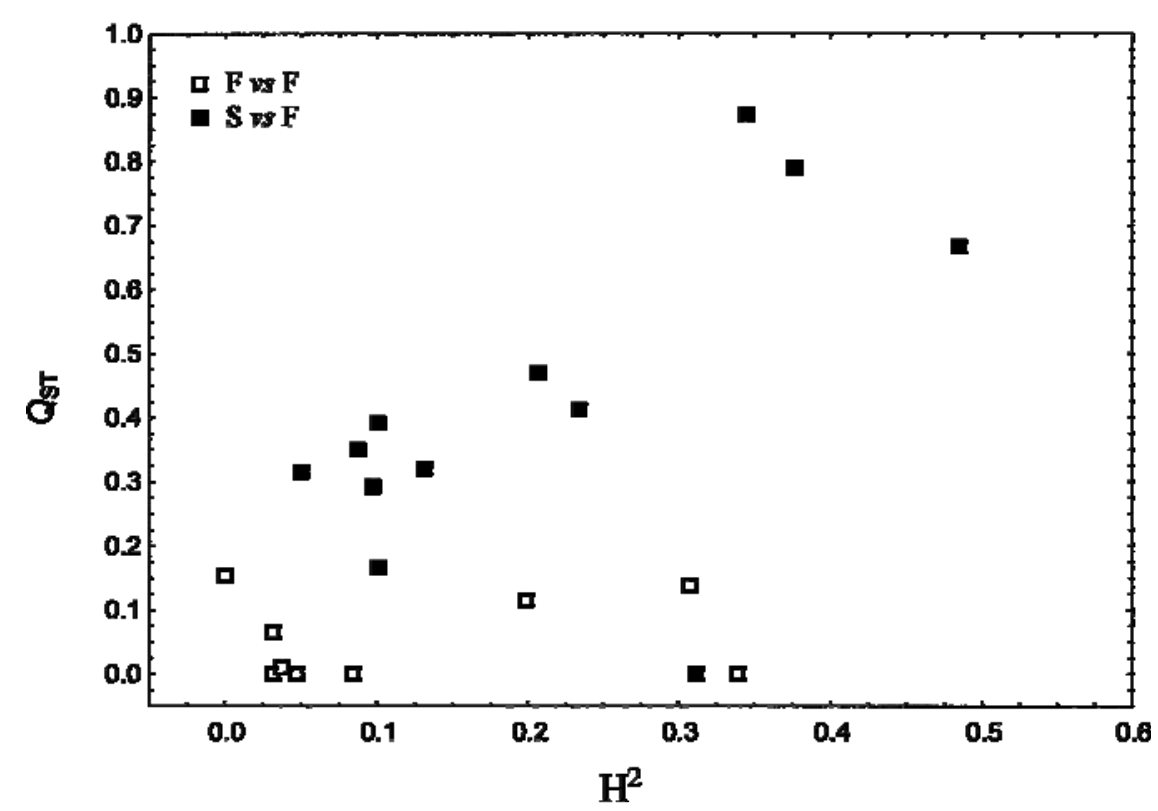

FIG. 2. Relationships between estimates of pairwise populational subdivision $\left(Q_{\mathrm{ST}}\right)$ and the average heritability within populations for embryo survival at the different treatments (see Table 1). Filled squares are pairwise comparisons between brackish and freshwater populations $\left(N=12\right.$, including 1998 , half-sibs experiment, $\left.r_{\mathrm{s}}=0.599, P=0.039\right)$, whereas empty squares are between freshwater populations $\left(r_{\mathrm{s}}=-0.383, P=0.308, N=9\right)$.

divergence, since $c i_{G \mathrm{~W}}^{2}$ then includes portions of nonadditive variance (dominance plus epistasis) and variance due to maternal effects in addition to purely additive genetic variance. The effect of dominance variance on $Q_{\mathrm{ST}}$ estimates is unclear and could cause both an increase or decrease with neutral differentiation (Whitlock 1999). In our system, $Q_{\mathrm{ST}}$ increased with salinity even when only additive genetic variance was considered (half-sib analysis, oval in Fig. 1). The range of $Q_{\text {ST }}$ values between Saline 2 and Fresh 2 (half-sib) was shorter than the ranges shown by brackish-fresh population pairs in the full-sib design. This result is not expected considering that only additive variance was considered in the half-sib experiment. However, the within-population component for the highest salinity treatment in the half-sib experiment was similar to that observed for the full-sib one, whereas the between-population component was proportionally lower for the half-sib, thus resulting in a lower $Q_{\mathrm{ST}}$ (Table 2).

It is worth noting that much of the variation in $Q_{\mathrm{ST}}$ was associated with variation in combined heritability (Fig. 2). This relationship was more pronounced for the brackish-fresh population comparisons than for the comparisons between fresh populations. This similar association has been found in other organism (Lynch et al. 1999; but see Koskinen et al. 2002). Under the same population structure, the degree of genetic differentiation between populations for a trait under selection is a function of the magnitude of additive genetic variance (Falconer and Mackay 1996), but the degree of differentiation for a neutral trait is independent of its heritability (Lande 1992; Lynch 1994; Lynch et al. 1999). In our system, the lack of association between $Q_{\mathrm{ST}}$ and heritability in freshwater population pairs suggested that embryonic survival is driven by neutral forces in freshwater populations, whereas selection may be responsible for the brackish-freshwater divergence.
One potential source of uncertainty in our analysis concerns the uncontrolled nonadditive or maternal effects that may affect both within- and between-population components of variance. Results from the half-sib experiment revealed that this component is smaller in magnitude and probably does not bias our within-population estimates. However, between-population estimates of embryo survival were clearly affected by maternal effects as revealed by comparing reciprocal hybrids between Saline 2 and Fresh 2 populations (M. Tejedo, I. Gomez-Mestre, and R. Reques, unpubl. data). Consequently, it seems likely that the very high $Q_{\mathrm{ST}}$ estimates may be partly attributable to environmental variation.

The concurrent analysis of genetic variation at eight microsatellite loci in these populations of B. calamita provided a null hypothesis of neutral divergence to test against that of local adaptation (Lynch 1990; Schluter 2000). $Q_{\mathrm{ST}_{\mathrm{T}} \text {-values }}$ were not markedly different from $F_{\mathrm{ST}}$-values when comparing freshwater populations with each other, and, even at the highest salinity, $Q_{\mathrm{ST}}$ was only two-fold higher than $F_{\mathrm{ST}}$. However, $Q_{\mathrm{ST}}$ was clearly higher (over one order of magnitude) than $F_{\text {ST }}$ between brackish and freshwater populations. These results support the hypothesis of population differentiation under selection (local adaptation) over the null hypothesis of neutral divergence. In some cases quantitative and neutral molecular distances have been reported to show a significant positive correlation (Merilä 1997; Merilä and Crnokrak 2001; Steinger et al. 2002), in which case variation in molecular markers can be used as a predictor of the degree of quantitative differentiation. Some other systems, including the one described in this paper (Mantel tests, Fig. 1), do not show such correlation, and hence molecular markers become inaccurate predictors of variation in quantitative traits (Reed and Frankham 2001).

Genetic diversity at the eight microsatellite loci scored, 
measured as either number of polymorphic loci, mean number of alleles per locus, or allelic richness $\left(\mathrm{H}_{\mathrm{e}}\right)$, was higher for the populations studied here than that reported for other populations of $B$. calamita throughout its distribution (Rowe et al. 1998; Beebee and Rowe 2000). No evidence for an isolation-by-distance pattern of population differentiation was found, and $F_{\mathrm{ST}}$ estimates were lower than those among U.K. populations, even if some differed significantly from zero. This finding supports Beebee and Rowe's (2000) assertion that Iberia had been a Pleistocene refugium for B. calamita, from where it may have expanded northward in repeated events of recolonization. However, the small number of populations analyzed does not allow us to assume a lack of geographic substructure of neutral genetic variation in Iberian populations. The overall estimated level of differentiation among the five populations considered was relatively low $\left(F_{S T}=0.029\right)$, indicating that the populations have not been isolated for long periods of time. Specifically, estimated $F_{S T^{-}}$ values between Fresh 1 and either Saline 1 or Saline 2 were not significantly different from zero, suggesting that either they currently exchange some gene flow or they have stopped doing so in the recent past.

The pond basins of both Saline 1 and Saline 2 were formed 5000 years ago on Quaternary saline sediments (Martín-Serrano García 1986). Assuming that these ponds were colonized by $B$. calamita when newly formed, that they have been successfully breeding in them ever since (they have not; $M$. Tejedo and I. Gomez-Mestre, pers. obs.), and a generation time of two years (Tejedo et al. 1997), 2000 is a rough estimate of the maximum number of generations that salinity tolerance has required to evolve in these populations. In principle, gene flow can prevent the differentiation of populations under different selection pressures (Hanks and Denno 1994; Storfer and Sih 1998; Lenormand 2002), but strong selection can counterbalance gene flow so that the population(s) under selection may remain genetically distinct in the face of migration (Mopper et al. 1995; Mopper 1996; Nagy and Rice 1997). Gene flow might have precluded strong differentiation at neutral loci of the $B$. calamita populations studied, while intense selection maintained differences in salinity tolerance, as found for other organisms and traits (Rice and Hostert 1993; Merilä 1997; Bensch et al. 1999; Schneider et al. 1999; Luttikhuizen et al. 2003). Alternatively, if populations have become isolated only in the recent past, selection may have acted on genetic variation underlying salinity tolerance more rapidly than drift could act on neutral genetic variation.

In summary, salinity tolerance in the brackish water populations studied seems to have been under strong selection, causing their quantitative genetic differentiation from freshwater populations, despite lack of geographic isolation.

\section{ACKNOWLEDGMENTS}

We thank R. Reques, N. Pérez, and J. Hidalgo for their assistance in setting up the experiments; J. Muñoz, J. M. Arroyo, and J. A. Godoy for their help in optimizing the molecular assays; and P. Jordano for his unconditional support. We thank also T. J. C. Beebee for training IGM in microsatellite analysis. Thanks to participants in the Estación Biológica de Doñana discussion group for their suggestions.
This work was supported by grant PB96-0861 from Dirección General de Investigación Científica y Técnica conceded to MT and the predoctoral grant AP97 05421411 from the Dirección General de Enseñ anza Superior e Investigació n Científica to IGM. Thanks also to Consejería de Medio Ambiente de la Junta de Andalucía, and especially to B. Moreno and the staff of the Reservas Naturales de las Zonas Húmedas del Sur de Córdoba, and the Reserva Biológica de Doñana, for providing the corresponding permits and facilities.

\section{Literature Cited}

Balinsky, J. B. 1981. Adaptation of nitrogen metabolism to hypertonic environment in Amphibia. J. Exp. Zool. 215:335-350.

Beebee, T. J. C. 1985. Salt tolerances of natterjack toad (Bufo calamita) eggs and larvae from coastal and inland populations in Britain. Herpetol. J. 1:14-16.

Beebee, T. J. C., and G. Rowe. 2000. Microsatellite analysis of natterjack toad Bufo calamita Laurenti populations: consequences of dispersal from a Pleistocene refugium. Biol. J. Linn. Soc. 69:367-381.

Bennington, C., and J. B. McGraw. 1996. Environment-dependence of quantitative genetic parameters in Impatiens pallida. Evolution 50:1083-1097.

Bensch, S., T. Andersson, and S. Akesson. 1999. Morphological and molecular variation across a migratory divide in willow warblers, Phylloscopus trochilus. Evolution 53:1925-1935.

Bohonak, A. J. 2002. IBD (isolation by distance): a program for analyses of isolation by distance. J. Hered. 93:154-155.

Boutilier, R. G., D. F. Stiffler, and D. P. Toews. 1992. Exchange of respiratory gases, ions, and water in amphibious and aquatic amphibians. Pp. 81-124 in M. E. Feder and W. W. Burggren, eds. Environmental physiology of the amphibians. Univ. of Chicago Press, Chicago.

Brookfield, J. F. Y. 1996. A simple new method for estimating null allele frequency from heterozygote deficiency. Mol. Ecol. 5: 453-455.

Dieringer, D., and C. Schlotterer. 2003. Microsatellite analyser (MSA): a platform independent analysis tool for large microsatellite data sets. Mol. Ecol. Notes 3:167-169.

Endler, J. A. 1986. Natural selection in the wild. Princeton Univ. Press, Princeton, NJ.

Falconer, D. S., and T. F. C. MacKay. 1996. Introduction to quantitative genetics. 4th ed. Prentice Hall, Harlow, U.K.

Gomez-Mestre, I., and M. Tejedo. 2002. Geographic variation in asymmetric competition: a case study with two larval anuran species. Ecology 83:2102-2111.

. 2003. Local adaptation of an anuran amphibian to osmotically stressful environments. Evolution 57:1889-1899.

Gosner, K. L. 1960. A simplified table for staging anuran embryos and larvae with notes on identification. Herpetologica 16: 183-190.

Hanks, L. M., and R. F. Denno. 1994. Local adaptation in the armored scale insect Pseudacaulacaspis pentagona (Homoptera: Diaspididae). Ecology 75:2301-2310.

Hansen, M. M., E. E. Nielsen, and K.-L. D. Mensberg. 1997. The problem of sampling families rather than populations: relatedness among individuals in samples of juvenile brown trout Salmo trutta L. Mol. Ecol. 6:469-474.

Hoffmann, A. A., and J. Merilä. 1999. Heritable variation and evolution under favourable and unfavourable conditions. Trends Ecol. Evol. 14:96-101.

Hoffmann, A. A., and P. A. Parsons. 1991. Evolutionary genetics and environmental stress. Oxford Univ. Press, Oxford, U.K.

Jenkins, N. L., C. M. Sgrò, and A. A. Hoffmann. 1997. Environmental stress and the expression of genetic variation. Pp. 7996 in R. Bijlsma and V. Loeschcke, eds. Environmental stress, adaptation and evolution. Birkhäuser Verlag, Basel.

Kingsolver, J. G., H. E. Hoekstra, J. M. Hoekstra, D. Berrigan, S. N. Vignieri, C. E. Hill, A. Hoang, P. Gibert, and P. Beerli. 2001. 
The strength of phenotypic selection in natural populations. Am. Nat. 157:245-261.

Knapp, E. E., and K. J. Rice. 1998. Comparison of isozymes and quantitative traits for evaluating patterns of genetic variation in purple needlegrass (Nassella pulchra). Conserv. Biol. 12: 1031-1041.

Koskinen, M. T., T. O. Haugen, and C. R. Primmer. 2002. Contemporary fisherian life-history evolution in small salmonid populations. Nature 419:826-830.

Kuittinen, H., A. Mattila, and O. Savolainen. 1997. Genetic variation at marker loci and in quantitative traits in natural populations of Arabidopsis thaliana. Heredity 79:144-152.

Lande, R. 1992. Neutral theory of quantitative genetic variance in an island model with local extinction and colonization. Evolution 46:381-389.

Lee, C. E., and B. W. Frost. 2002. Morphological stasis in the Eurytemora affinis species complex (Copepoda: Temoridae). Hydrobiologia 480:111-128.

Lenormand, T. 2002. Gene flow and the limits to natural selection. Trends Ecol. Evol. 17:183-189.

Long, A. D., and R. S. Singh. 1995. Molecules versus morphology: the detection of selection acting on morphological characters along a cline in Drosophila melanogaster. Heredity 74:569-581.

Luttikhuizen, P. C., J. Drent, W. Van Delden, and T. Piersma. 2003. Spatially structured genetic variation in a broadcast spawning bivalve: quantitative vs. molecular traits. J. Evol. Biol. 16: 260-272.

Lynch, M. 1990. The rate of morphological evolution in mammals from the standpoint of the neutral expectation. Am. Nat. 136: 727-741.

- 1994. The neutral theory of phenotypic evolution. Pp. 471501 in L. Real, ed. Ecological genetics. Princeton Univ. Press, Princeton, NJ.

- 1996. A quantitative-genetic perspective on conservation issues. Pp. 471-501 in J. C. Avise and J. L. Hamrick, eds. Conservation genetics: case histories from nature. Chapman and Hall, New York.

Lynch, M., and B. Walsh. 1998. Genetics and the analysis of quantitative traits. Sinauer Associates, Sunderland, MA.

Lynch, M., M. Pfrender, K. Spitze, N. Lehman, J. Hicks, D. Allen, L. Latta, M. Ottene, F. Bogue, and J. Colbourne. 1999. The quantitative and molecular genetic architecture of a subdivided species. Evolution 53:100-110.

Martín-Serrano García, A. 1986. Benamejí. Hoja geológica 1: 50.000. [16-41]. Instituto Geológico y Minero de España.

McKay, J. K., and R. G. Latta. 2002. Adaptive population divergence: markers, QTL and traits. Trends Ecol. Evol. 17:285-291.

Merilä, J. 1997. Quantitative trait and allozyme divergence in the greenfinch (Carduelis chloris, Aves: Fringillidae). Biol. J. Linn. Soc. 61:243-266.

Merilä, J., and P. Crnokrak. 2001. Comparison of genetic differentiation at marker loci and quantitative traits. J. Evol. Biol. 14: 892-903.

Mitchell-Olds, T., and J. J. Rutledge. 1986. Quantitative genetics in natural plant populations: a review of the theory. Am. Nat. 127:379-402.

Mopper, S. 1996. Adaptive genetic structure in phytophagous insect populations. Trends Ecol. Evol. 11:235-238.

Mopper, S., M. Beck, D. Simberloff, and P. Stiling. 1995. Local adaptation and agents of selection in a mobile insect. Evolution 49:810-815.

Morgan, K. K., J. Hicks, K. Spitze, L. Latta, M. Pfrender, C. S. Weaver, M. Ottone, and M. Lynch. 2001. Patterns of genetic architecture for life-history traits and molecular markers in a subdivided species. Evolution 55:1753-1761.

Nagy, E. S., and K. J. Rice. 1997. Local adaptation in two subspecies of an annual plant: implications for migration and gene flow. Evolution 51:1079-1089.

Palo, J. U., R. B. O’Hara, A. T. Laugen, A. Laurila, C. R. Primmer, and J. Merilä. 2003. Latitudinal divergence of common frog (Rana temporaria) life history traits by natural selection: evidence from a comparison of molecular and quantitative genetic data. Mol. Ecol. 12:1963-1978.
Petit, C., H. Freville, A. Mignot, B. Colas, M. Riba, E. Imbert, S. Hurtrezbousses, M. Virevaire, and I. Olivieri. 2001. Gene flow and local adaptation in two endemic plant species. Biol. Conserv. 100:21-34.

Podolsky, R. H. 2001. Genetic variation for morphological and allozyme variation in relation to population size in Clarkia dudleyana, an endemic annual. Conserv. Biol. 15:412-423.

Podolsky, R. H., and T. P. Holtsford. 1995. Population structure of morphological traits in Clarkia dudleyana. I. Comparison of $F_{\mathrm{ST}}$ between allozymes and morphological traits. Genetics 140: 733-744.

Prout, T., and J. S. F. Barker. 1993. F statistics in Drosophila buzzatii: selection, population size and inbreeding. Genetics 134: 369-375.

Reed, D. H., and R. Frankham. 2001. How closely correlated are molecular and quantitative measures of genetic variation? A meta-analysis. Evolution 55:1095-1103.

Rice, W. R. 1989. Analyzing tables of statistical tests. Evolution 43:223-225.

Rice, W. R., and E. E. Hostert. 1993. Laboratory experiments on speciation: What have we learned in 40 years? Evolution 47: 1637-1653.

Roff, D. A. 1997. Evolutionary quantitative genetics. Chapman and Hall, New York.

Rousset, F. 1997. Genetic differentiation and estimation of gene flow from $F$-statistics under isolation by distance. Genetics 145: $1219-1228$.

Rowe, G. T., T. J. C. Beebee, and T. Burke. 1997. PCR primers for polymorphic microsatellite loci in the anuran amphibian Bufo calamita. Mol. Ecol. 6:401-402.

- 1998. Phylogeography of the natterjack toad Bufo calamita in Britain: genetic differentiation of native and translocated populations. Mol. Ecol. 7:751-760.

. 2000. A further four polymorphic microsatellite loci in the natterjack toad Bufo calamita. Conserv. Genet. 1:371-372.

SAS Institute. 1999. SAS/STAT software user's guide. Rel. 8.00. SAS Institute, Inc., Cary, NC.

Schluter, D. 2000. The ecology of adaptive radiation. Oxford Univ. Press, Oxford, U.K.

Schneider, C. J., T. B. Smith, B. Larison, and C. Moritz. 1999. A test of alternative models of diversification in tropical rainforests: ecological gradients vs. rainforest refugia. Proc. Natl. Acad. Sci. USA 96:13869-13873.

Schneider, S., D. Roessli, and L. Excoffier. 2000. Arlequin: a software for population genetics data analysis. Ver. 2.000. Genetics and Biometry Lab, Dept. of Anthropology, Univ. of Geneva, Geneva, Switzerland.

Shaw, R. G. 1987. Maximum-likelihood approaches applied to quantitative genetics of natural populations. Evolution 41: 812-826.

Shaw, R. G., and F. H. Shaw. 1994. Quercus: programs for quantitative genetic analysis using maximum likelihood. Available from the authors or via anonymous ftp from ftp://ftp.bio. indiana.edu: directory path biology/quantgen/quercus.

Simons, A. M., Y. Carriere, and D. A. Roff. 1998. The quantitative genetics of growth in a field cricket. J. Evol. Biol. 11:721-733.

Sinsch, U., R. Seine, and N. Sherif. 1992. Seasonal changes in the tolerance of osmotic stress in natterjack toads (Bufo calamita). Comp. Biochem. Physiol. 101A:353-360.

Spitze, K. 1993. Population structure in Daphnia obtusa: quantitative genetic and allozymic variation. Genetics 135:367-374.

Steinger, T., P. Haldimann, K. A. Leiss, and H. Müller-Schärer. 2002. Does natural selection promote population divergence? A comparative analysis of population structure using amplified fragment length polymorphism markers and quantitative traits. Mol. Ecol. 11:2583-2590.

Storfer, A. 1996. Quantitative genetics: a promising approach for the assessment of genetic variation in endangered species. Trends Ecol. Evol. 11:343-348.

Storfer, A., and A. Sih. 1998. Gene flow and ineffective antipredator behavior in a stream-breeding salamander. Evolution 52: $558-565$

Storz, J. F. 2002. Contrasting patterns of divergence in quantitative 
traits and neutral DNA markers: analysis of clinal variation. Mol. Ecol. 11:2537-2551.

Tejedo, M., R. Reques, and M. Esteban. 1997. Actual and osteochronological estimated age of natterjack toads. Herpetol. J. 7: 81-82.

Waldmann, P., and S. Andersson. 2000. Comparison of genetic (co)variance matrices within and between Scabiosa canescens and S. columbaria. J. Evol. Biol. 13:826-835.

Weir, B. S., and C. C. Cockerham. 1984. Estimating F-statistics for the analysis of population structure. Evolution 38:1358-1370.
Whitlock, M. C. 1999. Neutral additive genetic variance in a metapopulation. Genet. Res. Camb. 74:215-221.

Widén, B., S. Andersson, G.-Y. Rao, and M. Widen. 2002. Population divergence of genetic (co)variance matrices in a subdivided plant species, Brassica cretica. J. Evol. Biol. 15:961-970. Wright, S. 1951. The genetic structure of populations. Ann. Eugenic. 15:323-354.

Corresponding Editor: M. Ashley 